\title{
Decomposition Of $\beta$-Closed Sets In Supra Topological Spaces
}

\author{
S. Dayana Mary ${ }^{1}$ and N. Nagaveni ${ }^{2}$ \\ ${ }^{1,2}$ (Department of Mathematics, Coimbatore Institute of Technology, India)
}

Abstract: - In this paper, we introduce a new class of sets called supra $\beta$ - locally closed sets and new class of maps called supra $\beta$-locally continuous functions. Furthermore, we obtain some of their properties.

Keywords: - $S$ - $\beta$-LC sets, $S$ - $\beta$-LC* sets, $S$ - $\beta$-LC $C^{* *}$ sets, $S$ - $\beta$-L-continuous and $S$ - $\beta$-L-irresolute.

\section{INTRODUCTION}

Njastad [1] defined and studied $\beta$-sets in topological spaces. Bourbaki [2] defined a subset of space $(\mathrm{X}, \tau)$ is called locally closed, if it is the intersection of an open set and a closed set. In topological space, some classes of sets namely generalized locally closed sets were introduced and investigated by Balachandran et al. [3]. The notion of $\beta$-locally closed set in topological spaces was introduced by Gnanambal and Balachandran [4]. Mashhour et al. [5] introduced the supra topological spaces and studied S-continuous functions and $\mathrm{S}^{*}$-continuous functions. Ravi et al. [6] introduced and studied a class of sets and maps between topological spaces called supra $\beta$-open sets and supra $\beta$-continuous maps, respectively. Dayana Mary [7] introduce a new class of sets called supra generalized locally closed sets and new class of maps called supra generalized locally continuous functions. They also introduce a new class of sets called supra regular generalized locally closed sets [8] and S-RGL-continuous functions.

In this paper we introduce the concept of supra $\beta$-locally closed sets and study its basic properties. Also we introduce the concepts of supra $\beta$-locally continuous maps and investigate several properties for these classes of maps.

\section{PRELIMINARIES}

Throughout this paper, $(\mathrm{X}, \tau),(\mathrm{Y}, \sigma)$ and $(\mathrm{Z}, \eta)$ (or simply, $\mathrm{X}, \mathrm{Y}$ and $\mathrm{Z}$ ) represent topological space on which no separation axioms are assumed, unless explicitly stated. For a subset $\mathrm{A}$ of $(\mathrm{X}, \tau), \mathrm{cl}(\mathrm{A})$ and int $(\mathrm{A})$ represent the closure of $\mathrm{A}$ with respect to $\tau$ and the interior of $A$ with respect to $\tau$, respectively. Let $P(X)$ be the power set of $X$. The complement of $A$ is denoted by $\mathrm{X}-\mathrm{A}$ or $\mathrm{A}^{\mathrm{c}}$.

Now we recall some Definition:s and results which are useful in the sequel.

Definition:: $2.1[5,9]$

Let $X$ be a non-empty set. The subfamily $\mu \subseteq P(X)$ is said to a supra topology on $X$ if $X \in \mu$ and $\mu$ is closed under arbitrary unions. The pair $(X, \mu)$ is called a supra topological space.

The elements of $\mu$ are said to be supra open in $(X, \mu)$. Complement of supra open sets are called supra closed sets. Definition:: 2.2 [9]

Let $A$ be a subset $(X, \mu)$. Then

(i) The supra closure of a set $\mathrm{A}$ is, denoted by $c l^{\mu}(A)$, defined as $c l^{\mu}(A)=\cap\{\mathrm{B}: \mathrm{B}$ is a supra closed and $\mathrm{A} \subseteq \mathrm{B}\}$.

(ii) The supra interior of a set $\mathrm{A}$ is, denoted by $i n t^{\mu}(A)$, defined as $\operatorname{int}^{\mu}(A)=\cup\{\mathrm{B}: \mathrm{B}$ is a supra open and $\mathrm{B} \subseteq \mathrm{A}\}$.

Definition:: 2.3 [5]

A Let $(X, \tau)$ be a topological space and $\mu$ be a supra topology of $X$. We call $\mu$ is a supra topology associated with $\tau$ if $\tau \subseteq \mu$.

Definition:: $2.4[10]$

Let $(\mathrm{X}, \tau)$ and $(\mathrm{Y}, \sigma)$ be two topological spaces and $\tau \subseteq \mu$. A function $\mathrm{f}:(\mathrm{X}, \tau) \rightarrow(\mathrm{Y}, \sigma)$ is called supra continuous, if the inverse image of each open set of $\mathrm{Y}$ is a supra open set in $\mathrm{X}$.

Definition:: $2.5[11]$

Let $(\mathrm{X}, \tau)$ and $(\mathrm{Y}, \sigma)$ be two topological spaces and $\mu$ and $\lambda$ be supra topologies associated with $\tau$ and $\sigma$ respectively. A function $f:(X, \tau) \rightarrow(Y, \sigma)$ is said to be supra irresolute, if $f^{-1}(A)$ is supra open set of $X$ for every supra open set $\mathrm{A}$ in $\mathrm{Y}$.

Definition:: $2.6[6]$

Let $(\mathrm{X}, \mu)$ be a supra topological space. A subset $\mathrm{A}$ of $\mathrm{X}$ is called supra $\beta$-open if $\mathrm{A} \subseteq c l^{\mu}\left(\operatorname{int}^{\mu}\left(c l^{\mu}(A)\right)\right)$.

$\beta \mathrm{O}(\mathrm{X})$

The complement of supra $\beta$-open set is called supra $\beta$-closed. The class of all supra $\beta$-open sets is denoted by $S$ -

Definition:: 2.7 [6]

Let $A$ be a subset $(X, \mu)$. Then

(i) The supra $\beta$-closure of a set $\mathrm{A}$ is, denoted by $c l_{\beta}^{\mu}(A)$, defined as $c l_{\beta}^{\mu}(A)=\cap\{\mathrm{B}: \mathrm{B}$ is a supra $\beta$-closed and $\mathrm{A} \subseteq$ B \}.

(ii) The supra $\beta$-interior of a set $\mathrm{A}$ is, denoted by $\operatorname{int}_{\beta}^{\mu}(A)$, defined as $\operatorname{int}_{\beta}^{\mu}(A)=\cup\{\mathrm{B}: \mathrm{B}$ is a supra $\beta$-open and $\mathrm{B} \subseteq$ A\}.

III. SUPRA $\beta$-LOCALLY CLOSED SETS

In this section, we introduce the notions of supra $\beta$-locally closed sets and discuss some of their properties. 
Definition:: 3.1

Let $(X, \mu)$ be a supra topological space. A subset $A$ of $(X, \mu)$ is called supra $\beta$-locally closed set (briefly supra $\beta$ -

LC set), if $A=U \cap V$, where $U$ is supra $\beta$-open in $(X, \mu)$ and $V$ is supra $\beta$-closed in $(X, \mu)$. Remark: 3.2

The collection of all supra generalized locally closed sets of $X$ will be denoted by S- $\beta-\mathrm{LC}(\mathrm{X})$.

\section{Definition: 3.3}

Every supra $\beta$-closed set (resp. supra $\beta$-open set) is S- $\beta$-LC.

For a subset $A$ of supra topological space $(X, \mu), A \in S-\beta-L C^{*}(X, \mu)$, if there exist a supra $\beta$-open set $U$ and a supra closed set $\mathrm{V}$ of $(\mathrm{X}, \mu)$, respectively such that $\mathrm{A}=\mathrm{U} \cap \mathrm{V}$.

\section{Definition: 3.4}

For a subset $A$ of $(X, \mu), A \in S-\beta$-LC**(X, $\mu)$, if there exist an supra open set $U$ and a supra $\beta$-closed set $V$ of $(X$, $\mu$ ), respectively such that $A=U \cap V$.

\section{Definition: 3.5}

Let $(X, \mu)$ be a supra topological space. If the space $(X, \mu)$ is called a supra $B$-space, then the collection of all supra $\beta$-open subsets of $(X, \mu)$ is closed under finite intersection.

Example 3.6

Let $X=\{a, b, c, d\}$ and $\mu=\{\phi, X,\{a\},\{a, b\},\{b, c\},\{a, b, c\}\}$. Then $S-\beta O(X)=\{\phi, X,\{a\},\{b\},\{a, b\},\{a$, $c\},\{a, d\},\{a, b, c\},\{a, b, d\},\{a, c, d\}\}$. Hence $(X, \mu)$ is supra $B$-space.

\section{Definition: 3.7} Theorem: 3.8

Let $\mathrm{A}, \mathrm{B} \subseteq(\mathrm{X}, \mu)$. Then $\mathrm{A}$ and $\mathrm{B}$ are said to be supra $\beta$-separated if $\mathrm{A} \cap c l_{\beta}^{\mu}(B)=\mathrm{B} \cap c l_{\beta}^{\mu}(A)=\phi$.

Let $A$ be a subset of $(X, \mu)$. If $A \in S-\beta-L C *(X, \mu)$ or $A \in S-\beta-L C * *(X, \mu)$, then $A$ is $S-\beta-L C$.

Proof: The proof is obvious by Definition:s and the following example.

Example 3.9

Let $X=\{a, b, c, d\}$ and $\mu=\{\phi, X,\{a\},\{a, b\},\{b, c\},\{a, b, c\}\}$. Then $S-\beta-L C(X, \mu)=S-\beta-L C *(X, \mu)=P(X)$. S$\beta-L C^{* *}(X, \mu)=P(X)-\{\{a, d\},\{a, c, d\}\}$.

Theorem: 3.10

For a subset $\mathrm{A}$ of $(X, \mu)$, the following are equivalent:

(i) $\quad \mathrm{A} \in \mathrm{S}-\beta-\mathrm{LC} *(\mathrm{X}, \mu)$

(ii) $\quad \mathrm{A}=\mathrm{U} \cap c l^{\mu}(A)$, for some supra $\beta$-open set $\mathrm{U}$.

(iii) $\quad c l^{\mu}(A)-\mathrm{A}$ is supra $\beta$-closed.

(iv) $\quad \mathrm{A} \cup\left[\mathrm{X}-c l^{\mu}(A)\right]$ is supra $\beta$-open.

Proof: $\quad$ (i) $\Rightarrow$ (ii): Given $A \in \mathrm{S}-\beta-\mathrm{LC} *(\mathrm{X}, \mu)$

Then there exist a supra $\beta$-open subset $\mathrm{U}$ and a supra closed subset $\mathrm{V}$ such that $\mathrm{A}=\mathrm{U} \cap \mathrm{V}$. Since $\mathrm{A} \subset \mathrm{U}$ and $\mathrm{A} \subset$ $c l^{\mu}(A), \mathrm{A} \subset \mathrm{U} \cap c l^{\mu}(A)$.

Conversely, $c l^{\mu}(A) \subset \mathrm{V}$ and hence $\mathrm{A}=\mathrm{U} \cap \mathrm{V} \supset \mathrm{U} \cap\left(c l^{\mu}(A)\right)$. Therefore, $\mathrm{A}=\mathrm{U} \cap c l^{\mu}(A)$

(ii) $\Rightarrow(\mathrm{i}):$ Let $\mathrm{A}=\mathrm{U} \cap c l^{\mu}(A)$, for some supra $\beta$-open set $\mathrm{U}$. Then, $c l^{\mu}(A)$ is supra closed and hence $\mathrm{A}=\mathrm{U} \cap$ $c l^{\mu}(A) \in \mathrm{S}-\mathrm{GLC}^{*}(\mathrm{X}, \mu)$.

(ii) $\Rightarrow$ (iii): $\quad$ Let $\mathrm{A}=\mathrm{U} \cap c l^{\mu}(A)$, for some supra $\beta$-open set $\mathrm{U}$. Then $\mathrm{A} \in \mathrm{S}$ - $\beta$-LC* $(\mathrm{X}, \mu)$. This implies $\mathrm{U}$ is supra $\beta$-open and $c l^{\mu}(A)$ is supra closed. Therefore, $c l^{\mu}(A)-\mathrm{A}$ is supra $\beta$-closed.

(iii) $\Rightarrow$ (ii): $\quad$ Let $\mathrm{U}=\mathrm{X}-\left[c l^{\mu}(A)-\mathrm{A}\right]$. $\mathrm{By}$ (iii), $\mathrm{U}$ is supra $\beta$-open in $\mathrm{X}$. Then $\mathrm{A}=\mathrm{U} \cap c l^{\mu}(A)$ holds.

(iii) $\Rightarrow$ (iv): $\quad$ Let $\mathrm{Q}=c l^{\mu}(A)-\mathrm{A}$ be supra $\beta$-closed. Then $\mathrm{X}-\mathrm{Q}=\mathrm{X}-\left[c l^{\mu}(A)-\mathrm{A}\right]=\mathrm{A} \cup\left[\left(\mathrm{X}-c l^{\mu}(A)\right]\right.$. Since $\mathrm{X}-\mathrm{Q}$ is supra $\beta$-open, $\mathrm{A} \cup\left[\mathrm{X}-c l^{\mu}(A)\right]$ is supra $\beta$-open.

(iv) $\Rightarrow$ (iii): $\quad$ Let $\mathrm{U}=\mathrm{A} \cup\left[\left(\mathrm{X}-c l^{\mu}(A)\right]\right.$. Since $\mathrm{X}-\mathrm{U}$ is supra $\beta$-closed and $\mathrm{X}-\mathrm{U}=c l^{\mu}(A)-\mathrm{A}$ is supra $\beta$-closed.

Theorem: 3.11

For a subset $A$ of $(X, \mu)$, the following are equivalent:

(i) $\quad \mathrm{A} \in \mathrm{S}-\beta-\mathrm{LC}(\mathrm{X}, \mu)$

(ii) $\mathrm{A}=\mathrm{U} \cap c l_{\beta}^{\mu}(A)$, for some supra $\beta$-open set $\mathrm{U}$.

(iii) $c l_{\beta}^{\mu}(A)-\mathrm{A}$ is supra $\beta$-closed.

(iv) $\mathrm{A} \cup\left[\mathrm{X}-c l_{\beta}^{\mu}(A)\right]$ is supra $\beta$-open.

(v) $\mathrm{A} \subseteq \operatorname{int}_{\beta}^{\mu}\left(\mathrm{A} \cup\left[\mathrm{X}-c l_{\beta}^{\mu}(A)\right]\right.$.

Proof: $\quad$ (i) $\Rightarrow$ (ii): $\quad$ Given $A \in S-\beta-L C(X, \mu)$

Then there exist a supra $\beta$-open subset $\mathrm{U}$ and a supra $\beta$-closed subset $\mathrm{V}$ such that $\mathrm{A}=\mathrm{U} \cap \mathrm{V}$. Since $\mathrm{A} \subset \mathrm{U}$ and $\mathrm{A} \subset$ $c l_{\beta}^{\mu}(A), \mathrm{A} \subset \mathrm{U} \cap c l_{\beta}^{\mu}(A)$.

Conversely $c l_{\beta}^{\mu}(A) \subset \mathrm{V}$ and hence $\mathrm{A}=\mathrm{U} \cap \mathrm{V} \supset \mathrm{U} \cap c l_{\beta}^{\mu}(A)$. Therefore $\mathrm{A}=\mathrm{U} \cap c l_{\beta}^{\mu}(A)$.

(ii) $\Rightarrow$ (i): Let $\mathrm{A}=\mathrm{U} \cap c l_{\beta}^{\mu}(A)$, for some supra $\beta$-open set $\mathrm{U}$. Then we have, $c l_{\beta}^{\mu}(A)$ is supra $\beta$-closed and hence $\mathrm{A}=\mathrm{U}$ $\cap c l_{\beta}^{\mu}(A) \in \mathrm{S}-\beta-\mathrm{LC} *(\mathrm{X}, \mu)$.

(ii) $\Rightarrow$ (iii): Let $\mathrm{A}=\mathrm{U} \cap c l_{\beta}^{\mu}(A)$, for some supra $\beta$-open set $\mathrm{U}$.

Then $\mathrm{A} \in \mathrm{S}$ - $\beta$-LC $(\mathrm{X}, \mu)$. This implies $\mathrm{U}$ is supra $\beta$-open and $c l_{\beta}^{\mu}(A)$ is supra $\beta$-closed. Therefore, $c l_{\beta}^{\mu}(A)-\mathrm{A}$ is supra $\beta$ closed.

(iii) $\Rightarrow$ (ii): Let $\mathrm{U}=\mathrm{X}-\left[c l_{\beta}^{\mu}(A)-\mathrm{A}\right]$. By (iii), $\mathrm{U}$ is supra $\beta$-open in $\mathrm{X}$. Then $\mathrm{A}=\mathrm{U} \cap c l_{\beta}^{\mu}(A)$ holds. 
(iii) $\Rightarrow$ (iv): Let $\mathrm{Q}=c l_{\beta}^{\mu}(A)-\mathrm{A}$ be supra $\beta$-closed. Then $\mathrm{X}-\mathrm{Q}=\mathrm{X}-\left[c l_{g}^{\mu}(A)-\mathrm{A}\right]=\mathrm{A} \cup\left[\left(\mathrm{X}-c l_{\beta}^{\mu}(A)\right]\right.$. Since $\mathrm{X}-\mathrm{Q}$ is supra $\beta$ open, $\mathrm{A} \cup\left[\mathrm{X}-c l_{\beta}^{\mu}(A)\right]$ is supra $\beta$-open.

(vi) $\Rightarrow$ (iii): Let $\mathrm{U}=\mathrm{A} \cup\left[\left(\mathrm{X}-c l_{\beta}^{\mu}(A)\right]\right.$. Since $\mathrm{X}-\mathrm{U}$ is supra $\beta$-closed and $\mathrm{X}-\mathrm{U}=c l_{\beta}^{\mu}(A)-\mathrm{A}$ is supra $\beta$-closed.
(vi) $\Rightarrow$ (v):
Since $\mathrm{U}=\mathrm{A} \cup\left[\left(\mathrm{X}-c l_{\beta}^{\mu}(A)\right]\right.$ is supra- $\beta$-open, $\mathrm{A} \subseteq i n t_{\beta}^{\mu}\left(\mathrm{A} \cup\left[\left(\mathrm{X}-c l_{g}^{\mu}(A)\right]\right)\right.$.

(v) $\Rightarrow$ (iv):

It is obvious.

Theorem: 3.12

Let $(X, \mu)$ be a supra B-space and $A \subset X$ be S- $\beta$-LC. Then

(i) $\quad \operatorname{int}_{\beta}^{\mu}(A) \in \mathrm{S}-\beta-\mathrm{LC}(\mathrm{X}, \mu)$.

(ii) $\quad c \quad c l_{\beta}^{\mu}(A)$ is contained in a supra $\beta$-closed set.

(iii) $\quad \mathrm{A}$ is supra $\beta$-open if $c l_{\beta}^{\mu}(A)$ is supra $\beta$-open.

Proof: (i) $\quad$ Let $\mathrm{A}=\mathrm{U} \cap c l_{\beta}^{\mu}(A)$, for some supra $\beta$-open set $\mathrm{U}$. Now, $\operatorname{int} t_{\beta}^{\mu}(A)=\operatorname{int} t_{\beta}^{\mu}\left(U \cap c l_{\beta}^{\mu}(A)\right)=\operatorname{int} t_{\beta}^{\mu}(U) \cap$ $\operatorname{int}_{\beta}^{\mu}\left(c l_{\beta}^{\mu}(A)\right)=\operatorname{int} t_{\beta}^{\mu}(U) \cap c l_{\beta}^{\mu}\left(\operatorname{int}_{\beta}^{\mu}(A)\right)$. Thus $\operatorname{int}_{\beta}^{\mu}(A)$ is S- $\beta$-LC.

(ii) $\quad c l_{\beta}^{\mu}(A)=c l_{\beta}^{\mu}\left(U \cap c l_{\beta}^{\mu}(A)\right) \subset c l_{\beta}^{\mu}(U) \cap c l_{\beta}^{\mu}(A)$ which is a supra $\beta$-closed set.

(iii) $\quad \operatorname{int}_{\beta}^{\mu}(A)=\operatorname{int}_{\beta}^{\mu}\left(U \cap c l_{\beta}^{\mu}(A)\right)=\operatorname{int}_{\beta}^{\mu}(U) \cap \operatorname{int}_{\beta}^{\mu}\left(c l_{\beta}^{\mu}(A)\right)=\mathrm{U} \cap c l_{\beta}^{\mu}(A)=\mathrm{A}$ since $c l_{\beta}^{\mu}(A)$ is supra $\beta$ -

open. Hence A is supra $\beta$-open.

Theorem: 3.13

If $A \subset B \subset X$ and $B$ is $S-\beta-L C$, then there exists a S- $\beta$-LC set $C$ such that $A \subset C \subset B$.

Proof: Immediate.

Theorem: 3.14

For a subset $\mathrm{A}$ of $(\mathrm{X}, \mu)$, if $\mathrm{A} \in \mathrm{S}-\beta-\mathrm{LC} * *(\mathrm{X}, \mu)$, then there exist an supra open set $\mathrm{G}$ such that $\mathrm{A}=\mathrm{G} \cap c l^{\mu}(A)$.

Proof: $\quad$ Let $A \in S-\beta-L C^{* *}(X, \mu)$. Then $A=G \cap V$, where $G$ is supra open set and $V$ is supra $\beta$-closed set. Then $A=G \cap V$ $\Rightarrow \mathrm{A} \subset \mathrm{G}$. Obviously, $\mathrm{A} \subset c l^{\mu}(A) . \therefore \mathrm{A} \subset \mathrm{G} \cap c l^{\mu}(A)----(1)$

Also we have $c l^{\mu}(A) \subset \mathrm{V}$. This implies $\mathrm{A}=\mathrm{G} \cap \mathrm{V} \supset \mathrm{G} \cap c l^{\mu}(A) \Rightarrow \mathrm{A} \supset \mathrm{G} \cap c l^{\mu}(A)$----- (2)

From (1) and (2), we get $\mathrm{A}=\mathrm{G} \cap c l^{\mu}(A)$.

Theorem: 3.15

For a subset $\mathrm{A}$ of $(\mathrm{X}, \mu)$, if $\mathrm{A} \in \mathrm{S}-\beta$-LC** $(\mathrm{X}, \mu)$, then there exist an supra open set $\mathrm{G}$ such that $\mathrm{A}=\mathrm{G} \cap c l_{\beta}^{\mu}(A)$.

Proof: $\quad$ Let $A \in S-\beta-L C * *(X, \mu)$.

Then $\mathrm{A}=\mathrm{G} \cap \mathrm{V}$, where $\mathrm{G}$ is supra open set and $\mathrm{V}$ is supra $\beta$-closed set.

Then $\mathrm{A}=\mathrm{G} \cap \mathrm{V} \Rightarrow \mathrm{A} \subset \mathrm{G}$. Then $\mathrm{A} \subset c l_{\beta}^{\mu}(A)$. Therefore, $\mathrm{A} \subset \mathrm{G} \cap c l_{\beta}^{\mu}(A)$----- (1)

Also we have $c l_{\beta}^{\mu}(A) \subset \mathrm{V}$. This implies, $\mathrm{A}=\mathrm{G} \cap \mathrm{V} \supset \mathrm{G} \cap c l_{\beta}^{\mu}(A) \Rightarrow \mathrm{A} \supset \mathrm{G} \cap c l_{\beta}^{\mu}(A)$----- (2)

From (1) and (2), we get $\mathrm{A}=\mathrm{G} \cap c l_{\beta}^{\mu}(A)$.

Theorem: 3.16

Let $\mathrm{A}$ be a subset of $(\mathrm{X}, \mu)$. If $\mathrm{A} \in \mathrm{S}-\beta-\mathrm{LC} * *(\mathrm{X}, \mu)$, then $c l_{\beta}^{\mu}(A)-\mathrm{A}$ supra $\beta$-closed and $\mathrm{A} \cup\left[\left(\mathrm{X}-c l_{\beta}^{\mu}(A)\right]\right.$ is supra

$\beta$-open.

Proof: The proof is obvious from the Definition:s and results.

Remark 3.17

The converse of the above Theorem: need not be true as seen the following example. Example 3.18

Let $X=\{a, b, c, d\}$ and $\mu=\{\phi, X,\{a\},\{a, b\},\{b, c\},\{a, b, c\}\}$. Then $\{\phi, X,\{a\},\{b\},\{a, b\},\{a, c\},\{a, d\},\{a, b$, $c\},\{a, b, d\},\{a, c, d\}\}$ is the set of all supra $\beta$-closed sets in $X$ and $S-\beta-L C^{* *}(X, \mu)=P(X)-\{a, d\}$ and $\{a, c, d\}$. If $A=\{a$, $\mathrm{d}\}$, then $c l_{\beta}^{\mu}(A)-\mathrm{A}=\{\mathrm{c}\}$ is supra $\beta$-closed and $\mathrm{A} \cup\left[\left(\mathrm{X}-c l_{\beta}^{\mu}(A)\right]=\{\mathrm{a}, \mathrm{b}, \mathrm{d}\}\right.$ is supra $\beta$-open but $\mathrm{A} \notin \mathrm{S}-\beta$-LC**$(\mathrm{X}, \mu)$.

Theorem: 3.19

Suppose $(X, \mu)$ is a supra B-space. Let $A \in S-\beta-\operatorname{LC}(X, \mu)$ and $B \in S-\beta-L C(X, \mu)$. If $A$ and $B$ are supra $\beta$ separated, then $A \cup B \in S-\beta-L C(X, \mu)$.

Proof: $\quad$ Let $A \in S-\beta-L C(X, \mu)$ and $B \in S-\beta-L C(X, \mu)$. By Theorem: 2 , there exist supra $\beta$-open sets $P$ and $S$ of $(X, \mu)$ such that $\mathrm{A}=\mathrm{P} \cap c l^{\mu}(A)$ and $\mathrm{B}=\mathrm{S} \cap c l^{\mu}(B)$. Put $\left.\mathrm{L}=\mathrm{P} \cap\left[\mathrm{X}-c l^{\mu}(B)\right)\right]$ and $\mathrm{M}=\mathrm{S} \cap\left[\mathrm{X}-c l^{\mu}(A)\right]$. Then $\mathrm{L} \cap c l_{\beta}^{\mu}(A)=[\mathrm{P} \cap(\mathrm{X}-$ $\left.\left.c l_{\beta}^{\mu}(B)\right)\right] \cap c l_{\beta}^{\mu}(A)=\mathrm{P} \cap\left(c l_{\beta}^{\mu}(B)\right)^{c} \cap c l_{g}^{\mu}(A)=\mathrm{A} \cap\left(c l_{g}^{\mu}(B)\right)^{c}=\mathrm{A}$, since $\mathrm{A} \subset\left(c l_{\beta}^{\mu}(B)\right)^{c}$. Similarly, $\mathrm{M} \cap c l_{\beta}^{\mu}(B)=\mathrm{B}$. Then $\mathrm{L} \cap c l_{\beta}^{\mu}(B)=\phi$ and $\mathrm{M} \cap c l_{\beta}^{\mu}(A)=\phi$. Since $\mathrm{X}$ is a supra B-space, $\mathrm{L}$ and $\mathrm{M}$ are supra $\beta$-open. $(\mathrm{L} \cup \mathrm{M}) \cap \mathrm{L} \cap$ $c l_{\beta}^{\mu}(A \cup B)=(\mathrm{L} \cup \mathrm{M}) \cap\left(c l_{\beta}^{\mu}(A) \cup c l_{\beta}^{\mu}(B)\right)=\left(\mathrm{L} \cap c l_{\beta}^{\mu}(A)\right) \cup\left(\mathrm{L} \cap c l_{\beta}^{\mu}(B)\right) \cup\left(\mathrm{M} \cap c l_{\beta}^{\mu}(A)\right) \cup\left(\mathrm{M} \cap c l_{\beta}^{\mu}(B)\right)=\mathrm{A} \cup \mathrm{B}$. Therefore $\mathrm{A} \cup \mathrm{B} \in \mathrm{S}-\beta-\mathrm{LC}(\mathrm{X}, \mu)$.

Remark: 3.20

Example: 3.21

The following is one of the example of the above Theorem:

Consider the example 3.9. Let $\mathrm{A}=\{\mathrm{a}\}$ and $\mathrm{B}=\{\mathrm{b}\}$. Then $\mathrm{A}$ and $\mathrm{B}$ are supra $\beta$-separated, because if $\mathrm{A} \cap c l_{\beta}^{\mu}(B)=$ $\mathrm{B} \cap c l_{\beta}^{\mu}(A)=\phi$. Then $\mathrm{A} \cup \mathrm{B}=\{\mathrm{a}, \mathrm{b}\} \in \mathrm{S}-\beta-\mathrm{LC}(\mathrm{X}, \mu)$.

Definition: 3.22

Let $(X, \mu)$ be a supra topological space. A subset $A$ of $(X, \mu)$ is called supra $\beta$-dense, if $c l_{\beta}^{\mu}(B)=X$.

Definition: 3.23 

Example 3.24

A supra topological space $(X, \mu)$ is called supra $\beta$-submaximal, if every supra $\beta$-dense subset is supra $\beta$-open in $X$.

Consider the example 3.9. Here $\mathrm{X},\{\mathrm{a}, \mathrm{b}\},\{\mathrm{a}, \mathrm{b}, \mathrm{c}\}$ and $\{\mathrm{a}, \mathrm{b}, \mathrm{d}\}$ are the supra $\beta$-dense sets and also supra $\beta$-open sets in $\mathrm{X}$. Therefore $\mathrm{X}$ is supra $\beta$-submaximal.

Theorem: 3.25

A supra topological space $(X, \mu)$ is supra $\beta$-submaximal if and only if $P(X)=S-\beta-L C(X)$ holds.

Proof: $\quad$ Necessity: Let $\mathrm{A} \in \mathrm{P}(\mathrm{X})$ and $\mathrm{G}=\mathrm{A} \cup\left[\mathrm{X}-c l_{\beta}^{\mu}(A)\right]$. Then $c l_{\beta}^{\mu}(G)=$ and so $\mathrm{G}$ is supra $\beta$-dense and hence supra $\beta$ open by assumption. By Theorem: 3.11, A $\in$ S- $\beta$-LC $(X)$. Hence $P(X)=S-\beta-L C(X)$.

Sufficiency: $\quad$ Let every subset of $\mathrm{X}$ be supra $\beta$-locally closed. Let A be supra $\beta$-dense in $\mathrm{X}$. Then $c l_{\beta}^{\mu}(A)=$ $\mathrm{X}$. Now $\mathrm{A}=\mathrm{A} \cup\left[\mathrm{X}-c l_{\beta}^{\mu}(A)\right]$. By Theorem: 3.11, $\mathrm{A}$ is supra $\beta$-open. Hence $\mathrm{X}$ is supra $\beta$-submaximal.

Theorem: 3.26

Let $(X, \mu)$ and $(Y, \lambda)$ be the supra topological spaces.

(1) If $M \in S-\beta-L C(X, \mu)$ and $N \in S-\beta-L C(Y, \lambda)$, then $M \times N \in S-\beta-L C(X \times Y, \mu \times \lambda)$.

(2) If $\mathrm{M} \in \mathrm{S}-\beta-\mathrm{LC} *(\mathrm{X}, \mu)$ and $\mathrm{N} \in \mathrm{S}-\beta-\mathrm{LC} *(\mathrm{Y}, \lambda)$, then $\mathrm{M} \times \mathrm{N} \in \mathrm{S}-\beta-\mathrm{LC} *(\mathrm{X} \times \mathrm{Y}, \mu \times \lambda)$.

(3) If $M \in S-\beta-L C^{* *}(X, \mu)$ and $N \in S-\beta-L C * *(Y, \lambda)$, then $M \times N \in S-\beta-L C * *(X \times Y, \mu \times \lambda)$.

Proof: $\quad$ Let $M \in S-S L C(X, \mu)$ and $N \in S-\beta-L C(Y, \lambda)$. Then there exist a supra semi-open sets $P$ and $P^{\prime}$ of $(X, \mu)$ and $(Y$, $\lambda$ ) and supra semi-closed sets $Q$ and $Q^{\prime}$ of $(X, \mu)$ and $(Y, \lambda)$ respectively such that $M=P \cap Q$ and $N=P^{\prime} \cap Q^{\prime}$. Then $M \times$ $\mathrm{N}=\left(\mathrm{P} \times \mathrm{P}^{\prime}\right) \cap\left(\mathrm{Q} \times \mathrm{Q}^{\prime}\right)$ holds. Hence $\mathrm{M} \times \mathrm{N} \in \mathrm{S}-\beta$-LC $(\mathrm{X} \times \mathrm{Y}, \mu \times \lambda)$.

Similarly, the proofs of (2) and (3) follow from the Definition:s.

\section{SUPRA GENERALIZED LOCALLY CONTINUOUS FUNCTIONS}

In this section we define a new type of functions called Supra $\beta$-locally continuous functions (S- $\beta$-L-continuous functions), supra $\beta$-locally irresolute functions and study some of their properties.

Definition: 4.1

Let $(\mathrm{X}, \tau)$ and $(\mathrm{Y}, \sigma)$ be two topological spaces and $\tau \subseteq \mu$. A function $\mathrm{f}:(\mathrm{X}, \tau) \rightarrow(\mathrm{Y}, \sigma)$ is called S- $\beta$-Lcontinuous (resp., S- $\beta$-L* - continuous, resp., S- $\beta$-L** - continuous), if $\mathrm{f}^{-1}(\mathrm{~A}) \in \mathrm{S}-\beta-\mathrm{LC}(\mathrm{X}, \mu),\left(\right.$ resp., $\mathrm{f}^{-1}(\mathrm{~A}) \in \mathrm{S}-\beta-\mathrm{LC} *$ $(\mathrm{X}, \mu)$, resp., $\left.\mathrm{f}^{-1}(\mathrm{~A}) \in \mathrm{S}-\beta-\mathrm{LC} * *(\mathrm{X}, \mu)\right)$ for each $\mathrm{A} \in \sigma$.

Definition: 4.2

Let $(\mathrm{X}, \tau)$ and $(\mathrm{Y}, \sigma)$ be two topological spaces and $\mu$ and $\lambda$ be a supra topologies associated with $\tau$ and $\sigma$ respectively. A function $f:(X, \tau) \rightarrow(Y, \sigma)$ is said to be $S-\beta$-L-irresolute (resp., S- $\beta$-L*- irresolute, resp., S- $\beta$ - $L^{* *}$ irresolute) if $\mathrm{f}^{-1}(\mathrm{~A}) \in \mathrm{S}-\beta$-LC $(\mathrm{X}, \mu)$, (resp., $\mathrm{f}^{-1}(\mathrm{~A}) \in \mathrm{S}-\beta-\mathrm{LC} *(\mathrm{X}, \mu)$, resp., $\mathrm{f}^{-1}(\mathrm{~A}) \in \mathrm{S}-\beta$-LC $\left.* *(X, \mu)\right)$ for each $\mathrm{A} \in \mathrm{S}-\beta-\mathrm{LC}$ $(\mathrm{Y}, \lambda)$ (resp., $\mathrm{A} \in \mathrm{S}-\beta$-LC* $(\mathrm{Y}, \lambda)$, resp., $\mathrm{A} \in \mathrm{S}-\beta-\mathrm{LC} *(\mathrm{Y}, \lambda)$ ).

Theorem: 4.3

Let $(\mathrm{X}, \tau)$ and $(\mathrm{Y}, \sigma)$ be two topological spaces and $\mu$ be a supra topology associated with $\tau$. Let $\mathrm{f}:(\mathrm{X}, \tau) \rightarrow(\mathrm{Y}, \sigma)$ be a function. If $\mathrm{f}$ is $\mathrm{S}-\beta-\mathrm{L}^{*}$-continuous or $\mathrm{S}-\beta-\mathrm{L}^{* *}$-continuous, then it is $\mathrm{S}-\beta$-L-continuous.

Proof: The proof is trivial from the Definition:s.

Theorem: 4.4

Let $(\mathrm{X}, \tau)$ and $(\mathrm{Y}, \sigma)$ be two topological spaces and $\mu$ and $\lambda$ be a supra topologies associated with $\tau$ and $\sigma$ respectively. Let $\mathrm{f}:(\mathrm{X}, \mu) \rightarrow(\mathrm{Y}, \sigma)$ be a function. If $\mathrm{f}$ is $\mathrm{S}-\beta$-L-irresolute (respectively $\mathrm{S}-\beta-\mathrm{L}^{*}-$ irresolute, respectively S$\beta$-L**-irresolute), then it is $\mathrm{S}-\beta$-L-continuous. (respectively S- $\beta$ - $\mathrm{L}^{*}$-continuous, respectively $\mathrm{S}-\beta$ - $\mathrm{L}$ - $*$-continuous).

Proof: By the Definition:s the proof is immediate.

Remark 4.5 Example 4.6

Converse of Theorem: 4.3 need not be true as seen from the following example.

Let $\mathrm{X}=\mathrm{Y}=\{\mathrm{a}, \mathrm{b}, \mathrm{c}, \mathrm{d}\}$ with $\tau=\{\phi, \mathrm{X},\{\mathrm{a}, \mathrm{b}, \mathrm{c}\}\}, \sigma=\{\{\phi, \mathrm{Y},\{\mathrm{a}, \mathrm{b}, \mathrm{d}\}\}$ and $\mu=\{\phi, \mathrm{X},\{\mathrm{a}, \mathrm{c}\},\{\mathrm{b}, \mathrm{c}\},\{\mathrm{a}, \mathrm{b}, \mathrm{c}\}$, $\{a, b, d\},\{b, c, d\}\}$. Define $f:(X, \mu) \rightarrow(Y, \sigma)$ by $f(a)=a, f(b)=c, f(c)=d$ and $f(d)=b$. Here $f$ is not $S-\beta-L^{* *}-$ continuous, but it is $\mathrm{S}-\beta$-L-continuous. Also $\mathrm{f}$ is not $\mathrm{S}-\beta-\mathrm{L}^{* *}$-continuous, but it is and $\mathrm{S}-\beta-\mathrm{L}^{*}$ - continuous.

Remark 4.7

The following example provides a function which is $S-\beta-L^{*} *_{-}$continuous function but not $S-\beta-L^{* *}$ - irresolute function.

Example 4.8

Let $\mathrm{X}=\mathrm{Y}=\{\mathrm{a}, \mathrm{b}, \mathrm{c}, \mathrm{d}\}$ with $\tau=\{\phi, \mathrm{X},\{\mathrm{b}, \mathrm{c}\},\{\mathrm{a}, \mathrm{b}, \mathrm{c}\}\}, \sigma=\{\{\phi, \mathrm{Y},\{\mathrm{a}, \mathrm{b}, \mathrm{c}\}\}, \mu=\{\phi, X,\{\mathrm{a}, \mathrm{c}\},\{\mathrm{b}, \mathrm{c}\},\{\mathrm{a}, \mathrm{b}, \mathrm{c}\}$, $\{a, b, d\},\{b, c, d\}\}$ and $\lambda=\{\phi, Y,\{a\},\{b, c\},\{a, b, c\},\{a, b, d\}\}$. Let $f:(X, \mu) \rightarrow(Y, \sigma)$ be the identity map. Here $f$ is not $S-$ $\beta-\mathrm{L}^{*}$ - irresolute, but it is $\mathrm{S}-\beta-\mathrm{L}^{*}$ - continuous.

Theorem: 4.9

Let $\mathrm{f}:(\mathrm{X}, \tau) \rightarrow(\mathrm{Y}, \sigma)$ be supra $\beta$-LC-continuous and $\mathrm{A}$ be supra $\beta$-closed in $\mathrm{X}$. Then the restriction $\mathrm{f} \mid \mathrm{A}: \mathrm{A} \rightarrow \mathrm{Y}$ is S- $\beta$-L-continuous.

Proof: $\quad$ Let $\mathrm{U}$ be supra open in Y. Then $f^{-1}(U)$ in supra $\beta$-LC in $\mathrm{X}$. So $f^{-1}(U)=\mathrm{G} \cap \mathrm{F}$ where $\mathrm{G}$ is supra $\beta$-open and $\mathrm{F}$ is supra $\beta$-closed in $\mathrm{X}$. Now $(f / A)^{-1}(U)=(\mathrm{G} \cap \mathrm{F}) \cap \mathrm{A}=\mathrm{G} \cap(\mathrm{F} \cap \mathrm{A})(\operatorname{resp} .(\mathrm{G} \cap \mathrm{A}) \cap \mathrm{F})$ where $\mathrm{F} \cap \mathrm{A}$ is supra $\beta$-closed (resp. $\mathrm{G} \cap \mathrm{A}$ is supra $\beta$-open $)$ in $\mathrm{X}$. Therefore $(f / A)^{-1}(U)$ is supra $\beta$-LC in $\mathrm{X}$. Hence $\mathrm{f} \mid \mathrm{A}$ is supra $\beta$-L-continuous.

Theorem: 4.10 continuous.

A space $(X, \mu)$ is supra $\beta$-submaximal if and only if every function having $(X, \mu)$ as domain is supra $\beta$-L- 
Proof: $\quad$ Necessity: $\quad$ Let $(X, \mu)$ be supra $\beta$-submaximal. Then $\beta$-LC $(X)=P(X)$ by Theorem: 3.25. Let $\mathrm{f}:(X, \mu) \rightarrow$ $(\mathrm{Y}, \lambda)$ be a function and $\mathrm{A} \in \sigma$. Then $f^{-1}(A) \in \mathrm{S}-\beta$ - $\mathrm{LC}(\mathrm{X})$ and so $\mathrm{f}$ is $\mathrm{S}-\beta$-L-continuous.

Sufficiency: Let every function having $(X, \mu)$ as domain be supra $\beta$-L-continuous. Let $Y=\{0,1\}$ and $\sigma=$ $\{\phi, Y,\{0\}\}$. Let $A \subset(X, \mu)$ and $f:(X, \mu) \rightarrow(Y, \lambda)$ be defined by $f(x)=0$ if $x \in A$ and $f(x)=1$ if $x \notin A$. Since $f$ is supra $\beta$-Lcontinuous, $A \in S-\beta$ - $L C(X, \mu)$. Therefore $P(X)=S-\beta$ - $L C(X)$ and so $X$ is supra $\beta$-submaximal by Theorem: 3.25 .

Theorem: 4.11

If $\mathrm{g}: \mathrm{X} \rightarrow \mathrm{Y}$ is $\mathrm{S}-\beta$-L-continuous and $\mathrm{h}: \mathrm{Y} \rightarrow \mathrm{Z}$ is supra continuous, then hog $: \mathrm{X} \rightarrow \mathrm{Z}$ is $\mathrm{S}-\beta$-L-continuous.

Proof: Let $\mathrm{g}: \mathrm{X} \rightarrow \mathrm{Y}$ is S-GL - continuous and $\mathrm{h}: \mathrm{Y} \rightarrow \mathrm{Z}$ is supra continuous. By the Definition:s, $\mathrm{g}^{-1}(\mathrm{~V}) \in \mathrm{S}-\beta-\mathrm{LC}(\mathrm{X})$, $\mathrm{V} \in \mathrm{Y}$ and $\mathrm{h}^{-1}(\mathrm{~W}) \in \mathrm{Y}, \mathrm{W} \in \mathrm{Z}$. Let $\mathrm{W} \in \mathrm{Z}$. Then $(h \circ g)^{-1}(\mathrm{~W})=\left(\mathrm{g}^{-1} \mathrm{~h}^{-1}\right)(\mathrm{W})=\mathrm{g}^{-1}\left(\mathrm{~h}^{-1}(\mathrm{~W})\right)=\mathrm{g}^{-1}(\mathrm{~V})$, for $\mathrm{V} \in \mathrm{Y}$. From this, $(h \circ)^{-1}(\mathrm{~W})=\mathrm{g}^{-1}(\mathrm{~V}) \in \mathrm{S}-\mathrm{GLC}(\mathrm{X}), \mathrm{W} \in \mathrm{Z}$. Therefore, hog is $\mathrm{S}-\beta-\mathrm{L}$ - continuous.

Theorem: 4.12 continuous.

If $\mathrm{g}: \mathrm{X} \rightarrow \mathrm{Y}$ is $\mathrm{S}-\beta-\mathrm{L}-$ irresolute and $\mathrm{h}: \mathrm{Y} \rightarrow \mathrm{Z}$ is $\mathrm{S}-\beta$ - $\mathrm{L}$-continuous, then $\mathrm{h}$ o $\mathrm{g}: \mathrm{X} \rightarrow \mathrm{Z}$ is $\mathrm{S}-\beta$ - $\mathrm{L}-$

Proof: $\quad$ Let $\mathrm{g}: \mathrm{X} \rightarrow \mathrm{Y}$ is S- $\beta$-L - irresolute and $\mathrm{h}: \mathrm{Y} \rightarrow \mathrm{Z}$ is S- $\beta$-L-continuous. By the Definition:s, $\mathrm{g}^{-1}(\mathrm{~V}) \in \mathrm{S}-\beta$-LC $(X)$, for $V \in S-\beta-L C(Y)$ and $h^{-1}(W) \in S-\beta-L C(Y)$, for $W \in Z$. Let $W \in Z$. Then $(h o g)^{-1}(W)=\left(g^{-1} h^{-1}\right)(W)=g^{-1}\left(h^{-1}(W)\right)=$ $\mathrm{g}^{-1}(\mathrm{~V})$, for $\mathrm{V} \in \mathrm{S}-\beta-\mathrm{LC}(\mathrm{Y})$. This implies, $(\mathrm{hog})^{-1}(\mathrm{~W})=\mathrm{g}^{-1}(\mathrm{~V}) \in \mathrm{S}-\beta-\mathrm{LC}(\mathrm{X}), \mathrm{W} \in \mathrm{Z}$. Hence hog is S- $\beta$-L- continuous.

Theorem: 4.13

If $\mathrm{g}: \mathrm{X} \rightarrow \mathrm{Y}$ and $\mathrm{h}: \mathrm{Y} \rightarrow \mathrm{Z}$ are $\mathrm{S}-\beta-\mathrm{L}-$ irresolute, then $\mathrm{h}$ o $\mathrm{g}: \mathrm{X} \rightarrow \mathrm{Z}$ is also S- $\beta$ - $\mathrm{L}$ - irresolute.

Proof: By the hypothesis and the Definition:s, we have $\mathrm{g}^{-1}(\mathrm{~V}) \in \mathrm{S}-\beta-\mathrm{LC}(\mathrm{X})$, for $\mathrm{V} \in \mathrm{S}-\beta$-LC $(\mathrm{Y})$ and $\mathrm{h}^{-1}(\mathrm{~W}) \in \mathrm{S}-\beta-\mathrm{LC}$ $(Y)$, for $W \in S-\beta-L C(Z)$. Let $W \in S-\beta-L C(Z)$. Then $(h o g)^{-1}(W)=\left(g^{-1} h^{-1}\right)(W)=g^{-1}\left(h^{-1}(W)\right)=g^{-1}(V)$, for $V \in S-G L C(Y)$. Therefore, $(h \circ g)^{-1}(\mathrm{~W})=\mathrm{g}^{-1}(\mathrm{~V}) \in \mathrm{S}-\beta-\mathrm{LC}(\mathrm{X}), \mathrm{W} \in \mathrm{S}-\mathrm{GLC}(\mathrm{Z})$. Thus hog is S-GL - irresolute.

\section{REFERENCES}

[1]. O. Njastad, On some classes of nearly open sets, Pacific. J. Math., 15 (1965), 961-970.

[2]. N. Bourbaki, General Topology, Part 1, Addison-Wesley (Reading, Mass, 1966)

[3]. K Balachandran, P Sundaram and H Maki. Generalized locally closed sets and GLC-continuous functions, Indian J. Pure Appl. Math., 27 (3) (1996), 235-244.

[4]. Y. Gnanambal and K. Balachandran, $\beta$-closed sets and $\beta$ - LC-continuous functions, Mem. Fac. Sci. Kochi Univ. Math., (19) (1998), 35-44.

[5]. A S Mashhour, A A Allam, F S Mahmond and F H Khedr. On Supra topological spaces, Indian J.Pure and Appl. Math.,14(4) (1983), 502-610.

[6]. O. Ravi, G. Ramkumar and M. Kamaraj, On supra $\beta$-open sets and supra $\beta$-continuity on topological spaces proceed, National seminar held at sivakasi, India, (2011), 22-31.

[7]. S. Dayana Mary and N. Nagaveni, Decomposition of generalized closed sets in supra topological spaces, International Journal of Computer Application, Aug 2012, Accepted.

[8]. S. Dayana Mary and N. Nagaveni, On decomposition of regular generalized continuity in supra topological spaces, Asian Journal of Current Engineering and Maths, Aug 2012, Accepted.

[9]. O R Sayed and T Noiri. On supra b-open sets and supra b-continuity on topological spaces, European J. Pure and Appl. Math., 3(2) (2010), 295-302.

[10]. R. Devi, S. Sampathkumar and M. Caldas, On supra $\alpha$-open sets and S $\alpha$ - continuous functions, General Mathematics, 16(2) (2008), 77-84.

[11]. M. Kamaraj, G. Ramkumar and O. Ravi, On Supra quotient mappings, International Journal of Mathematical Archive, 3 (1) (2012), 245-252. 